\title{
Moving Faster than the COVID-19 Pandemic: The Rapid, Digital Transformation of a Public Health System
}

\author{
Clair Sullivan ${ }^{1,2}$ Ides Wong ${ }^{3}$ Emily Adams $^{3}$ Magid Fahim ${ }^{1,2}$ Jon Fraser $^{2}$ Gihan Ranatunga ${ }^{2}$ \\ Matthew Busato ${ }^{2}$ Keith McNeil ${ }^{3}$ \\ ${ }^{1}$ Centre for Health Services Research, University of Queensland, \\ Brisbane, Australia \\ 2 Digital Metro North, Metro North Hospital and Health Service, \\ Brisbane, Queensland, Australia \\ ${ }^{3}$ Queensland Department of Health, Brisbane, Queensland, Australia

\begin{abstract}
Address for correspondence Clair Sullivan, MBBS, MD, FRACP, FAIDH, Queensland Digital Health Research Group, Centre for Health Services Research, Faculty of Medicine, University of Queensland, Herston 4006, Brisbane, Queensland, Australia
\end{abstract}

Appl Clin Inform 2021;12:229-236.

Abstract

Keywords

- public health

- electronic health records and systems

- clinical information systems

- emergency and disaster care

- biosurveillance and case reporting
Background Queensland, Australia has been successful in containing the COVID-19 pandemic. Underpinning that response has been a highly effective virus containment strategy which relies on identification, isolation, and contact tracing of cases. The dramatic emergence of the COVID-19 pandemic rendered traditional paper-based systems for managing contact tracing no longer fit for purpose. A rapid digital transformation of the public health contact tracing system occurred to support this effort.

Objectives The objectives of the digital transformation were to shift legacy systems (paper or standalone electronic systems) to a digitally enabled public health system, where data are centered around the consumer rather than isolated databases. The objective of this paper is to outline this case study and detail the lessons learnt to inform and give confidence to others contemplating digitization of public health systems in response to the COVID-19 pandemic.

Methods This case study is set in Queensland, Australia. Universal health care is available. A multidisciplinary team was established consisting of clinical informaticians, developers, data strategists, and health information managers. An agile "pair-programming" approach was undertaken to application development and extensive change efforts were made to maximize adoption of the new digital workflows. Data governance and flows were changed to support rapid management of the pandemic.

Results The digital coronavirus application (DCOVA) is a web-based application that securely captures information about people required to quarantine and creates a multiagency secure database to support a successful containment strategy.

Conclusion Most of the literature surrounding digital transformation allows time for significant consultation, which was simply not possible under crisis conditions. Our observation is that staff was willing to adopt new digital systems because the reason for change (the COVID-19 pandemic) was clearly pressing. This case study highlights just how critical a unified purpose, is to successful, rapid digital transformation. received

November 21, 2020 accepted after revision January 22, 2021
DOI https://doi.org/ 10.1055/s-0041-1725186. ISSN 1869-0327.
(C) 2021. The Author(s).

This is an open access article published by Thieme under the terms of the Creative Commons Attribution-NonDerivative-NonCommercial License, permitting copying and reproduction so long as the original work is given appropriate credit. Contents may not be used for commercial purposes, or adapted, remixed, transformed or built upon.(https://creativecommons.org/ licenses/by-nc-nd/4.0/)

Georg Thieme Verlag KG, Rüdigerstraße 14, 70469 Stuttgart, Germany 


\section{Background and Significance}

Australia (and particularly Queensland) has been successful at "flattening the curve" and containing COVID-19 infection rates to a level commensurate with health system capacity. This response has been acknowledged as a globally successful COVID-19 response. ${ }^{1,2}$

COVID-19 has challenged traditional public health methods, as they were reliant on paper-based workflows, spreadsheets, and isolated databases. ${ }^{3}$ This pandemic presented a new challenge to public health, whereby intense public focus on the virus, a political and public demand for accurate, real time reporting on number of cases, combined with rapid spread and a 24/7 news cycle has fuelled an insatiable appetite for up-to-the minute information, and low tolerance to adjustments on reported numbers. Many organizations globally are facing similar challenges. ${ }^{4-8}$

It was necessary to shift the workflows and data management for the COVID-19 response from traditional siloed information systems, clinical registries, and paper-based workflows to creating a real-time integrated digital data flow to manage COVID-19. The usual processes and structures of a large-scale digital transformation project, such as staff and consumer engagement during the planning of the project, extensive consultation, planning, and detailed workflow training were simply unachievable in the crisis conditions of the pandemic. This digitization of public health workflows at scale to provide real time data was challenging, but essential to support containment efforts and minimize COVID-19 morbidity and mortality in our jurisdiction.

\section{Objective}

We implemented a real-time integrated digital and data workflow solution to underpin the multiagency effective management of COVID-19 in Queensland, Australia. This effort required: (1) significant shifts in workflows (shifting clinical staff from paper and isolated information systems to a rapidly developed digital workflow), (2) the creation of a "single source of truth" for COVID exposed consumers, and most importantly, (3) a cultural and governance shift across whole of government to center data collection around the exposed consumers rather than around individual agencies and departments. The aim of this case study is to describe the lessons learned during the rapid and iterative development of the digital coronavirus application (DCOVA), a key component of the digital ecosystem contributing to Queensland's successful COVID-19 containment response.

\section{Methods}

\section{Setting and Participants}

Queensland is a state of Australia containing approximately $5,129,996$ people. ${ }^{9}$ All public hospital care is funded by the state. Primary care is funded by the federal government. Pathology testing is conducted across the public hospitals and multiple private providers. The police service and the fire service were pressed into service to monitor the move- ments and compliance of consumers confined to quarantine at their own homes. ${ }^{1}$ The international borders were closed, and any interstate visitors were administered self-quarantine orders, legally ordering them to remain in quarantine for 14 days. They were monitored in place and subject to checks by the police and emergency services, and supported by community organizations as required.

\section{Approach}

Rapid workflow analysis was undertaken of the legacy processes for managing quarantine and issuing and monitoring public health orders and business requirements established. Working within the constraints of an environment of rapidly changing policy direction meant we had to implement new functionality at a pace that exceeded the rate of system requirements change. Traditional relay processes for health information and communication technology development were too slow for this process. We adopted a "pairprogramming" approach to expedite the development time, where the clinical informatician (medical and nursing backgrounds) and the developer worked together in real time to develop the application rather than laborious develop/review cycles. ${ }^{10}$ This accelerated the work significantly. Development occurred in the Microsoft Powerapps environment which allows configuration for both mobile and desktop devices, and a low-code strategy was followed by the in-house development team of eight people. Costs were minimal as existing staff and resources were diverted to the COVID effort, and no private contractors were needed. A continuous improvement approach has been taken, with continuous iterative improvements. Agility of development was essential as government policy changed rapidly, often changing quarantine criteria (which needed to be reflected in DCOVA immediately). This flexibility was created by having a dedicated development team on call continuously in a crisis environment.

\section{Testing, Training, and Support}

Given the critical nature of this application in a disaster situation, robust testing was undertaken in a development environment including rapid user acceptance testing. Training materials were developed in tandem and continuously updated and cached online. Didactic training and at the elbow support were also provided as per our previous protocols. $^{11}$

\section{Results}

\section{The Application}

The digital corona virus application (DCOVA) is a web-based application which securely captures information about people required to quarantine and creates a multiagency secure database. Persons considered to be at increased risk of infection-due to travelling from an identified virus hotpot or having close contact with a known case-met the definition of surveillance and are required by law to quarantine for 14 days. DCOVA allows public health officers and police officers to support quarantinees, ensuring they are safe 
and have access to the services they require. It also integrates with other digital systems in a cloud-based data warehouse (Microsoft Azure) for broader reporting, for example, by linking surveillance to quarantine to laboratory testing, enabling knowledge quarantined persons tested and the number of new cases outside quarantine. Currently, DCOVA is used by Queensland Health $(\mathrm{QH})$, Queensland Police Service (QPS) and Department Housing and Public Works (DHPW) staff. DCOVA user interface is shown below ( - Fig。 1 ).

\section{The Outcome}

Development of the initial minimal viable product took approximately 5 days. DCOVA reduced the time for collection of the mandatory dataset from 4 minutes to approximately 2 minutes, effectively halving the time required to complete the workflow. In the first 3 months of use, about 9,886 consumers were tracked via 10,224 entries by 155 individual users. Queensland and Australia have one of the lowest transmissions and mortality rates globally. At the time of writing, there are six COVID-related deaths in Queensland (population $\sim 5$ million), with an infection rate of 1:244

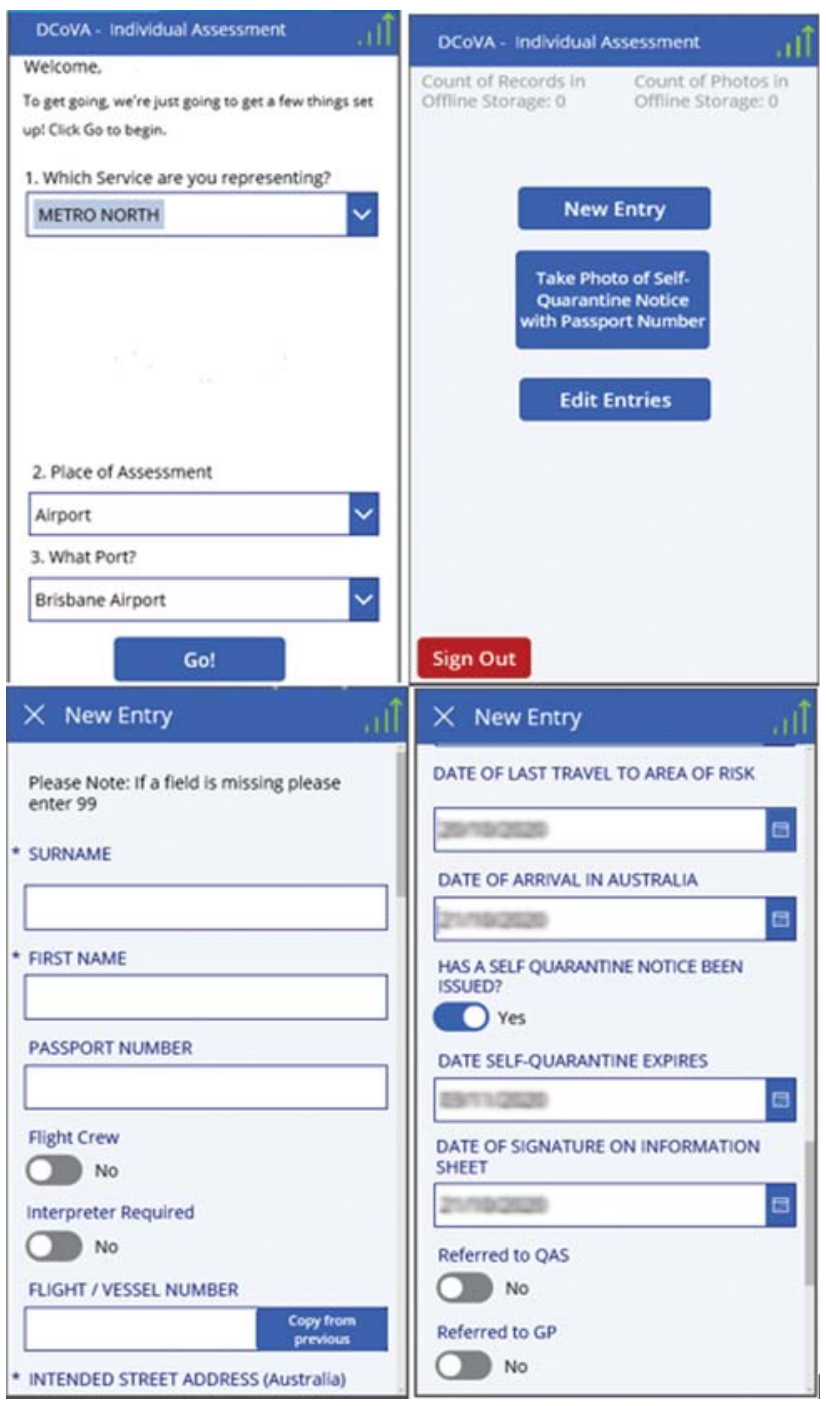

Fig. 1 Digital coronavirus application user interface. people (1:1,099 for Australia, and 1:9,942 globally; - Fig. 2). ${ }^{12,13}$ This is obviously due to multiple factors; however, rapid action would not have been possible without effective digital solutions to enable real-time data-driven decision-making.

\section{Lessons Learnt}

This application was developed under relatively pressured conditions. We had to learn many lessons during this process, outlined below.

\section{The Challenge of Continuously Changing Business Requirements due to COVID Policy Adjustments}

Due to the urgency around the implementation of the DCOVA system, the initial product was developed outside of the usual software development lifecycle and associated governance structures. Key challenges included a lack of clearly defined business requirements, complex business terminology, definition of minimum required (mandatory) data elements, uniquely identifying fields and relationships between entities. Challenges included working with stakeholders to avoid use of free-text fields for key linking elements and ensuring data elements collected were fit for purpose to avoid laborious workflows. Equally important was ensuring data input had sufficient identifying information to allow linkage and the avoidance of duplication. In addition, as a result of the rapidly evolving situation, the business requirements rapidly altered over the crisis response period, with often only a few hours' notice for major policy changes which required complex configuration management in DCOVA and workflow education and retraining for hundreds of staff.

\section{Multiple Versions of the Truth}

The single source of truth is a universal tenet of good information architecture, ${ }^{14,15}$ and in a complex environment of multiple systems and overlapping datasets, it is important that there is a single source of truth for a given set of information. The implications of out of date or inconsistent information are potentially far-reaching and undermine responsive services and public safety. The new digital workflows highlighted challenges for data integrity, for example, duplicate entries due to human error and previous delays in data entry. Prior to DCOVA, manual data entry and manual matching of consumer identities was resource intensive, error prone, and not conducive to informed decision-making in a rapidly changing environment. The single source of truth provided by the web-based shared application (DCOVA) largely resolved these issues.

\section{The Need for Inter-Agency Collaboration}

A series of global health emergencies, including Ebola and Zika, and now COVID-19 have normalized the need for data sharing and transparency. The criticality of rapidly available intelligence for public health responses supports the case for development of frameworks and systems to share data for the purposes of emergency preparedness. ${ }^{16}$ 


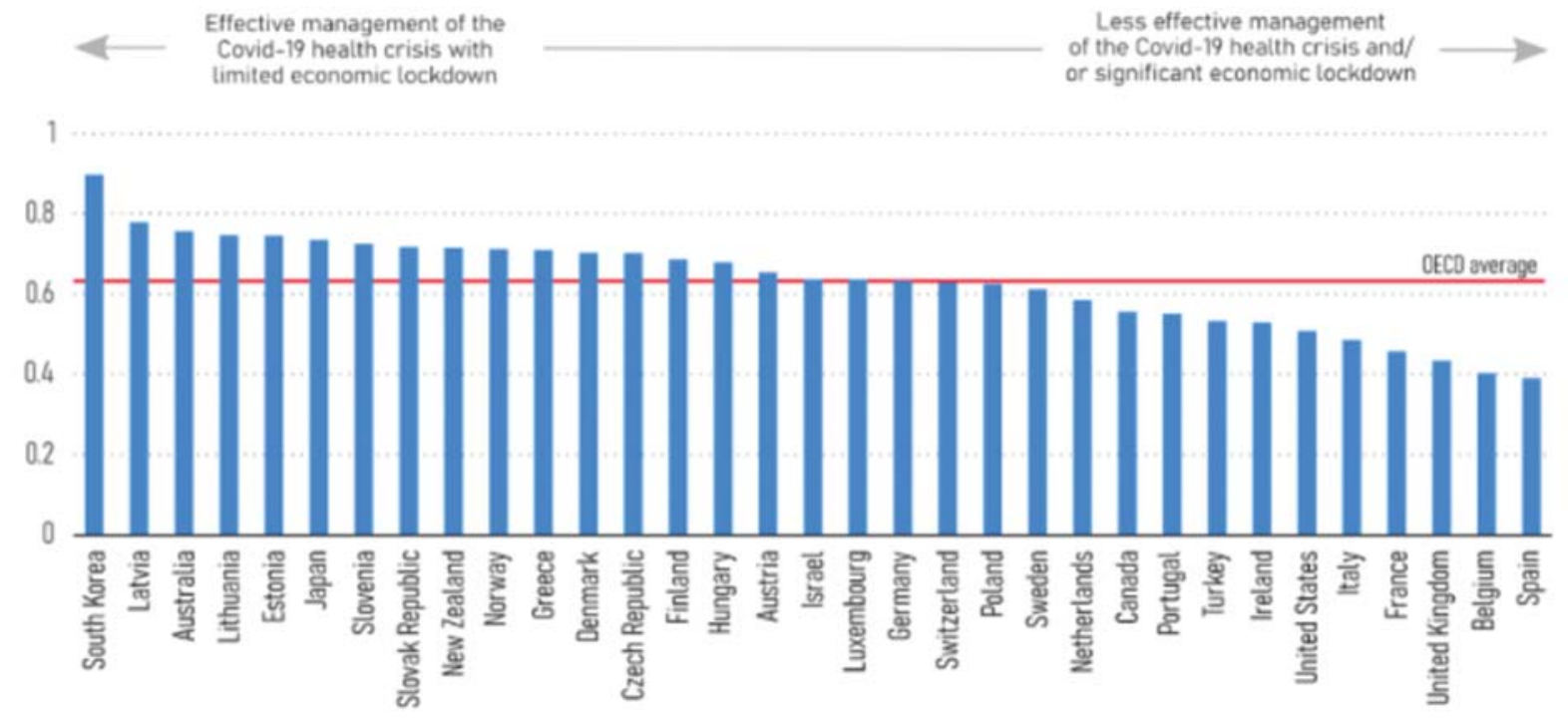

Source Sachs et al. 2020 Based on three key variables (1) martality rates. (D) Effective Reproduction rate and (3) Reduced mobility (based on Boogle mobility measurements, Bat(t)) Covers the period from Narch 4 to May 12,2020. See detaled methodology in section 12 of the report.

Fig. 2 Australia's response to COVID-19 ranked globally.

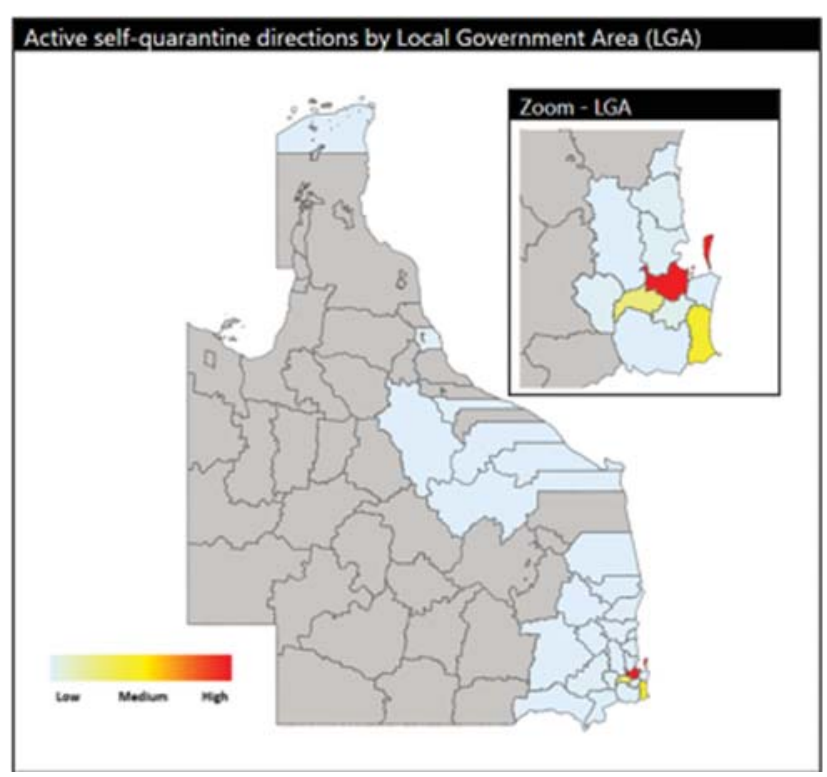

Fig. 3 Real-time heat maps of COVID-19 public health order load using digital coronavirus application data.

A timely containment response relies on digital cooperation between multiple agencies, responsibilities and has been outlined in -Table 1 below. The complexities and governance issues among this complex set of stakeholders required considerable effort to create a shared digital application (-Table 1).

In the absence of an overarching agreement for data sharing between agencies, individual sharing agreements must be established on a case-by-case basis. This is a resource intensive and complex legal process, which often detracts from the core work of agency staff, deters innovative and automated data exchange solutions, and results in delays in collaboration.

\section{Opportunities and Risks: Balancing Public Safety, Privacy, and Confidentiality}

To maximize collaboration across agencies and reduce duplication of efforts, navigating data-sharing agreements for DCOVA needed to happen rapidly. As an example, accurate data of the quarantinees needed to be shared among agencies to prevent multiple agencies from contacting the same person for welfare and compliance checks on the same day, potentially elevating levels of anxiety already experienced by these individuals.

Amendments were made to the Queensland Public Health Act 2005 legislation to allow for an extension of the declaration of a public health emergency from 7 to 90 days. This allowed agencies involved in responding to this public health emergency to have certainty that the emergency powers would endure. This change in legislation allowed the default position to shift from "how we could keep this data within Queensland Health environment" to "what are the necessary legislative, governance, and technological activities to enable information to flow through relevant agencies, balancing public safety, privacy, and confidentiality?" It was in the public interest to securely share the data across agencies. ${ }^{15}$ This was achieved by clearly articulating the costs of not sharing the data.

\section{Managing Digital Identity in a Crisis}

A single unique identifier was not available to manage the identity of consumers served with public health orders. Many consumers had no contact with health services previously and so did not have a record number. Creating a record at the airport or port was not deemed feasible. Multiple approaches were tried until name, and passport number was 
Table 1 Responsibilities of agencies that supported the COVID-19 response and required information from digital coronavirus application

\begin{tabular}{|c|c|}
\hline Areas & Responsibilities \\
\hline \multicolumn{2}{|l|}{ Agencies external to Queensland Health } \\
\hline Border force & $\begin{array}{l}\text { Control movement of people into Australia from international airports to stop } \\
\text { spread of COVID-19 }\end{array}$ \\
\hline Queensland Police Services & $\begin{array}{l}\text { Control movement of people into Queensland from domestic borders to stop } \\
\text { spread of COVID-19, and issuance of Quarantine Directions to identified } \\
\text { groups at these bordersInvestigation of quarantine direction breaches, } \\
\text { enforcement of quarantine }\end{array}$ \\
\hline $\begin{array}{l}\text { Department of Communities, Disability Ser- } \\
\text { vices, and Seniors }\end{array}$ & $\begin{array}{l}\text { Provide support during quarantine period if required (e.g., interpreters and } \\
\text { groceries) }\end{array}$ \\
\hline Queensland Health Public Health Units & Identify individuals requiring surveillance \\
\hline $\begin{array}{l}\text { Department of Justice and Attorney General } \\
\text { Department of Housing and Public Works }\end{array}$ & Provide quarantine direction notice information to Smart Service Queensland \\
\hline Smart Services Queensland & Contact members of the public for compliance monitoring \\
\hline \multicolumn{2}{|l|}{ Areas within Queensland Health } \\
\hline Health Contact Centre & Contact members of the public for clinical monitoring \\
\hline COVID-19 Compliance Cell & $\begin{array}{l}\text { Maintain direction notice information and provide reporting and compliance } \\
\text { checks } \\
\text { Receive notifications of changes to direction notices from executive groups }\end{array}$ \\
\hline Public Health Units & Perform contact tracing and issue Quarantine Direction Notices \\
\hline Hotel Fee Recovery & $\begin{array}{l}\text { Issue fees to individuals in quarantine for the provision of government } \\
\text { accommodation }\end{array}$ \\
\hline Hotel Fee Waiver & $\begin{array}{l}\text { Process fee waivers for individuals that are exempt from paying fees for } \\
\text { government quarantine accommodation }\end{array}$ \\
\hline
\end{tabular}

used to create an identifier. Passport numbers were common among all travelers and were static (as opposed to phone numbers, addresses). As these consumers then progressed to COVID-19 testing and contact with health care services, a probabilistic matching algorithm was used to interrogate existing records and pathology testing. It would have been much more efficient if we could have used a unique identifier created at the time of the serving of the public health orders. This would have allowed instant clear data linkage among public health, pathology providers, and health services, this however was a challenge in a transient, global consumer population.

\section{Discussion}

This large-scale digital transformation project occurred rapidly in crisis conditions. We had permission to "fail fast," and correct direction as we encountered issues with initial approaches. We followed a horizon approach to digital transformation, a conceptual framework which fortunately had already been established in our jurisdiction ( - Table 2; -Fig. 3). ${ }^{17}$

On reflection, many of the difficulties encountered map back to known syndromes of digital disruption in health care. ${ }^{18}$ We experienced digital deceleration as our initial digital procedures were slower than the paper processes, causing staff to initially resist adoption, particularly those with low digital literacy. As they navigated the learning curve, the digital processes became more efficient and adoption increased. We saw data discordance as we navigated mapping the new digital data elements back to the existing spreadsheets and identified duplicates and the need to define the elements in both systems. Digital churn was evident, with a small number of the staff members unable to transition to the digital workflows. We attempted to minimize this digital disruption by providing training and "at the elbow" support. Support from senior leadership within the organization was also critical to ensuring various teams "stay the course," and not revert back to manual workflows. DCOVA has now transitioned to business as usual, although ongoing improvements are planned to optimize function and workflow. Data workflows are now timely and allowing sharing of data securely and appropriately to maximize the efficiency of the COVID response (-Fig. 4). Global experience of informatics enabling COVID-19 response has recently shown that informatics is critical to a successful response, ${ }^{3,19,20}$ and the lessons learnt from this case study provide further weight to the premise that clinical informatics is an essential component of effective and timely pandemic containment.

\section{Conclusion}

Most of the literature surrounding digital transformation mandates time for significant change and training efforts, which was simply not possible under crisis conditions. Despite 
Table 2 Summary of the digital transformation of public health workflows by digital coronavirus application using the Queensland Digital Transformation Horizons

\begin{tabular}{|c|c|c|c|}
\hline Digital horizon & $\begin{array}{l}\text { Aspect of DCOVA } \\
\text { implementation }\end{array}$ & Pre & Post \\
\hline $\begin{array}{l}\text { Horizon one: } \\
\text { digitizing workflows }\end{array}$ & $\begin{array}{l}\text { Public health order } \\
\text { management } \\
\text { workflow }\end{array}$ & $\begin{array}{l}\text { Manual workflows, with a prevalence } \\
\text { of excel worksheets, and all the } \\
\text { inherent issues that come with } \\
\text { working in this way, including single- } \\
\text { user limitation, lack of intuitive user } \\
\text { interface, lack of standardization } \\
\text { between individual public health } \\
\text { units, limited data validation, slow, } \\
\text { inefficient, and high margin for error } \\
\text { and duplication } \\
\text { Additionally, spreadsheets across } \\
\text { public health units may not contain } \\
\text { consistent set of data elements which } \\
\text { causes downstream issues for } \\
\text { reporting and analysis }\end{array}$ & $\begin{array}{l}\text { Replacement of manual work- } \\
\text { flows with a multiuser mobile } \\
\text { application, with intuitive user } \\
\text { experience to allow for repeat- } \\
\text { able, scalable workflow }\end{array}$ \\
\hline \multirow[t]{4}{*}{$\begin{array}{l}\text { Horizon 2: data and } \\
\text { analytics }\end{array}$} & Data storage & $\begin{array}{l}\text { Excel files were stored on local or } \\
\text { network drives, version control was } \\
\text { manual (many variations of the one } \\
\text { spreadsheet existing), with informa- } \\
\text { tion transfer of information via email/ } \\
\text { teams, inability to scale for large } \\
\text { volumes of data } \\
\text { Lack of audit trail, no way to track } \\
\text { who has accessed/changed this data }\end{array}$ & $\begin{array}{l}\text { Implementation of an integrat- } \\
\text { ed database system enables a } \\
\text { single source of truth } \\
\text { Privacy and cybersecurity as- } \\
\text { sessment conducted during } \\
\text { operationalization of system, } \\
\text { including penetration testing } \\
\text { Access to data can be controlled } \\
\text { at a granular level, and access } \\
\text { and changes to data can be } \\
\text { tracked }\end{array}$ \\
\hline & Data governance & $\begin{array}{l}\text { Limited data governance and lack of } \\
\text { formal data management processes } \\
\text { lead to inconsistencies in reporting } \\
\text { and challenges guaranteeing data } \\
\text { integrity and reliability }\end{array}$ & $\begin{array}{l}\text { Each agency was granted ad- } \\
\text { ministrator rights to grant ac- } \\
\text { cess to approved users. All } \\
\text { access is tracked and accessible. } \\
\text { Secondary use of data governed } \\
\text { by existing policies and } \\
\text { procedures }\end{array}$ \\
\hline & Analytics outputs & $\begin{array}{l}\text { Siloed information } \\
\text { Excel spreadsheets of varying quality } \\
\text { Little recourse for data correction } \\
\text { Long lead times to collate, validate, } \\
\text { and prepare reporting outputs } \\
\text { Limited mechanisms for sharing an- } \\
\text { alytics outputs } \\
\text { No ability to centrally manage output } \\
\text { values, quality, and presentation }\end{array}$ & $\begin{array}{l}\text { Validated outputs based on data } \\
\text { with improved integrity, with } \\
\text { analyses to identify vulnerable } \\
\text { cohorts to target } \\
\text { A variety of predictive models, } \\
\text { and data visualizations, includ- } \\
\text { ing heatmaps are available } \\
\text { (- Fig. 3) }\end{array}$ \\
\hline & Data consumption & $\begin{array}{l}\text { Limited to individual public health } \\
\text { units that have access to } \\
\text { spreadsheets }\end{array}$ & $\begin{array}{l}\text { Multiuser, enterprise solution } \\
\text { allows state-wide Queensland } \\
\text { Health access, and access to } \\
\text { other departments as required, } \\
\text { including police and fire services } \\
\text { State-wide Queensland Health } \\
\text { access (with appropriate levels } \\
\text { of security), of up-to-date } \\
\text { information }\end{array}$ \\
\hline
\end{tabular}

Abbreviation: DCOVA, digital coronavirus application.

this, although we needed to continuously improve our efforts, the digital transformation now enables centralized, consumercentered streamlined data collection for real-time analysis to assist with pandemic management. Our observation is that staff and consumers were willing to rapidly change their work and behaviors because the reason for change (COVID-19 pandemic) was clearly articulated and pressing. This unified driver for change fuelled the digital transformation, despite the lack of traditional preparation measures usually deemed essential to successful transformation. In fact, many of the characteristics of this project (lack of time, limited change management resources) should have doomed this project to 


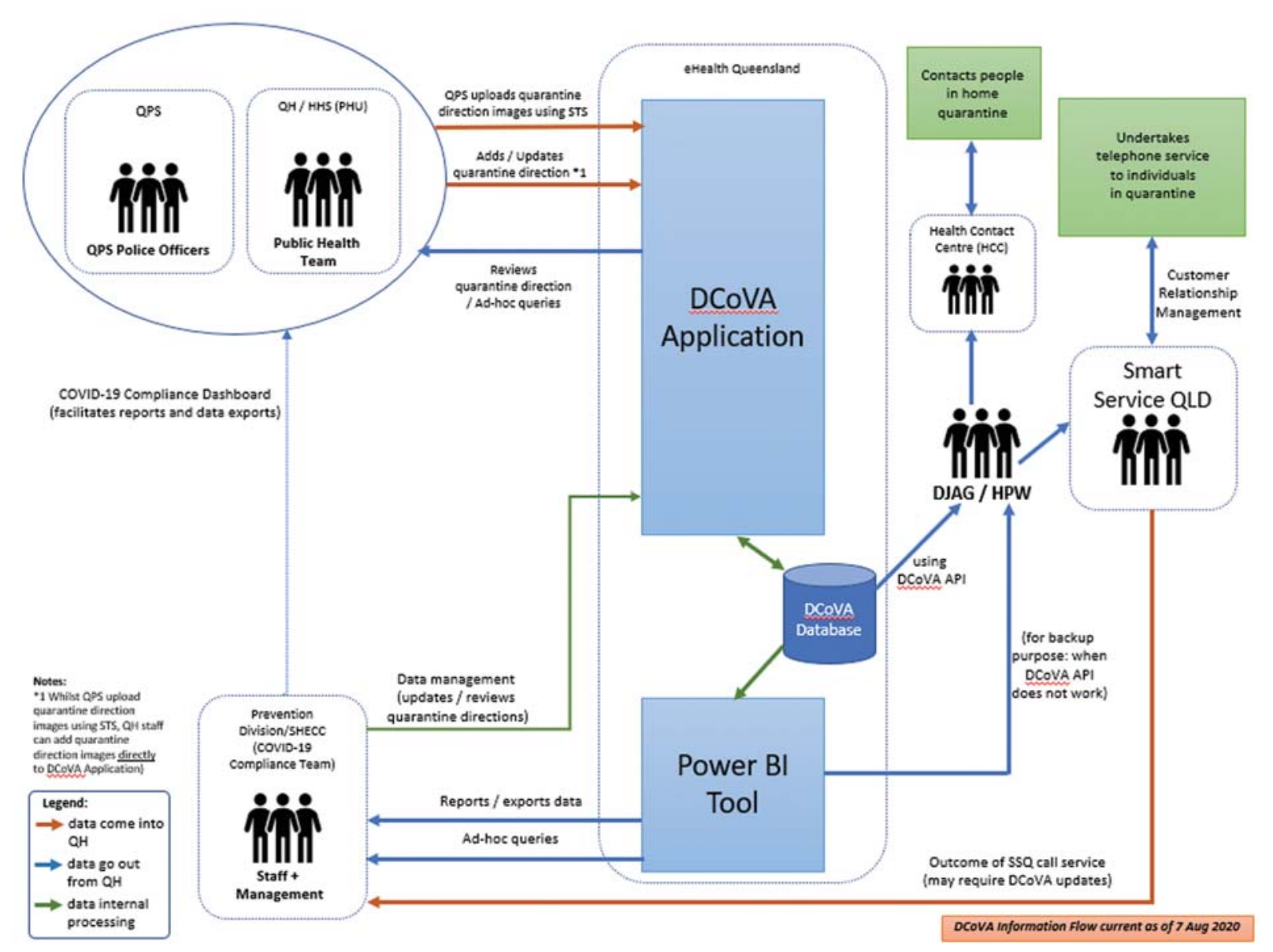

Fig. 4 Digital coronavirus application public health data flows.

failure. This case study highlights just how critical a unified purpose and vision, rather than project processes, is to successful, rapid digital transformation to support public health responses to pandemics.

\section{Clinical Relevance Statement}

COVID-19 is the most significant health issue facing this generation. An effective public health system which can collect and aggregate data in real time to display to decision makers and health system managers has been shown to be associated with a greater chance of successful "flattening of the curve." This case study outlines the clinical informatics underpinning one of the most successful global responses to COVID-19.

\section{Multiple Choice Questions}

1. Which of the following is true in regards to clinical informatics in a pandemic?

a. Clinical informatics is critical to an effective pandemic response.

b. New clinical informatics development is unlikely to be required. c. Paper-based systems are likely to be adequate to manage the data.

d. Spreadsheets are an effective way to manage pandemic contact tracing.

Correct Answer: Option a is the correct answer. Contemporary management of a pandemic requires a "single source of truth" to be collected in real time and available to all stakeholders in real time. This usually requires the development of customized digital workflows and applications to support the data collection, access, aggregation, and analysis in real time. Global experience shows that fragmented applications or spreadsheets are not adequate for effective real-time contact tracing and management.

2. When developing a new application in an urgent, pandemic response, which of the following is correct?

a. Usual lengthy consultation methods can be utilized to make sure all stakeholders are in agreement about the need for a new application.

b. Taking the time to develop a perfect solution that everyone is happy with is critical.

c. Taking an agile, iterative approach to development, with constant real-time feedback from end users has 
been shown to be successful, as business requirements are likely to rapidly evolve.

d. A waterfall approach to collecting all the business requirements from all the stakeholders is essential.

Correct Answer: Option c is the correct answer. Traditional "waterfall" approaches to application development are not fit for purpose in an emergency situation. A lengthy collection of business requirements is likely to be irrelevant within days due to rapid policy changes. An approach where clinical informaticians rapidly assess the clinical workflows and work with developers in real time to create a prototype that can be rapidly altered 24/7 in response to feedback from end users, policy makers and system managers has been shown to be successful in an emergent, pandemic situation. This requires skills and confidence to undertake an agile, iterative development processes, but is most likely to be able to respond effectively to a labile policy environment.

Protection of Human and Animal Subjects

No human subjects were directly involved in this project.

Funding

None.

Conflict of Interest

None declared.

\section{References}

1 Cave D. Vanquish the virus? Australia and New Zealand aim to show the way. 2020 Accessed September 19, 2020 at: https:// www.nytimes.com/2020/04/24/world/australia/new-zealandcoronavirus.html

2 Gan N. How did australia flatten its coronavirus curve? Restrictions easing as infection rate continues to fall. 2020; Fall. CNN, May 1. Accessed September 19, 2020 at: https://www.cnn.com/2020/05/ 01/asia/australia-coronavirus-success-intl-hnk/index.html

3 Bakken S. Informatics is a critical strategy in combating the COVID19 pandemic. J Am Med Inform Assoc 2020;27(06):843-844

4 Grange ES, Neil EJ, Stoffel M, et al. Responding to COVID-19: the UW Medicine Information Technology Services Experience. Appl Clin Inform 2020;11(02):265-275

5 Arvisais-Anhalt S, Lehmann CU, Park JY, et al. What the COVID-19 pandemic has reinforced: the need for accurate data. Clin Infect Dis 2020:ciaa1686
6 Altman RL, Anstett T, Simpson JR, Del Pino-Jones A, Lin CT, Pell J. Ambulatory Clinician's Guide to inpatient service: an innovative rapid onboarding strategy for the COVID-19 pandemic. Appl Clin Inform 2020;11(05):802-806

7 Hron JD, Parsons CR, Williams LA, Harper MB, Bourgeois FC. Rapid implementation of an inpatient telehealth program during the COVID-19 pandemic. Appl Clin Inform 2020;11(03):452-459

8 Medford RJ, Saleh SN, Sumarsono A, Perl TM, Lehmann CU. An "infodemic": leveraging high-volume twitter data to understand early public sentiment for the coronavirus disease 2019 outbreak. Open Forum Infect Dis 2020;7(07):a258

9 Office QGSs Office. 2020Queensland population counter 2020. Accessed September 19, 2020 at: https://www.qgso.qld.gov.$\mathrm{au} /$ statistics/theme/population/population-estimates/state-territories/qld-population-counter

10 Hannay J. The effectiveness of pair programming: a meta-analysis. Inf Softw Technol 2009;51(07):1110-1122

11 Sullivan C, Staib A, Ayre S, et al. Pioneering digital disruption: Australia's first integrated digital tertiary hospital. Med J Aust 2016;205(09):386-389

12 Google COVID19 transmission patterns. 2020 Accessed December 22, 2020 at: https://news.google.com/covid19/map?hl=enAU\&mid=\%2Fm\%2F0g39h\&gl=AU\&ceid=AU\%3Aen

13 UNESCO. How countries responded to COVID. 2020 Accessed November 14, 2020 at: https://en.unesco.org/covid19

14 Mandl KD, Kohane IS. Tectonic shifts in the health information economy. N Engl J Med 2008;358(16):1732-1737

15 Everson J, Patel V, Adler-Milstein J. Information blocking remains prevalent at the start of 21 century cures: results from a survey of health information exchange organizations. J Am Med Inform Assoc 2021:ocaa323

16 Kozlakidis Z, Abduljawad J, Al Khathaami AM, Schaper L, Stelling J. Global health and data-driven policies for emergency responses to infectious disease outbreaks. Lancet Glob Health 2020;8(11): e1361-e1363

17 Sullivan C, Staib A, McNeil K, Rosengren D, Johnson I. Queensland Digital Health Clinical Charter: a clinical consensus statement on priorities for digital health in hospitals. Aust Health Rev 2020;44 (05):661-665

18 Sullivan C, Staib A. Digital disruption 'syndromes' in a hospital: important considerations for the quality and safety of patient care during rapid digital transformation. Aust Health Rev 2017;(42): 294-298

19 Subbian V, Solomonides A, Clarkson M, et al. Ethics and informatics in the age of COVID-19: challenges and recommendations for public health organization and public policy. J Am Med Inform Assoc 2020

20 Reeves JJ, Hollandsworth HM, Torriani FJ, et al. Rapid response to COVID-19: health informatics support for outbreak management in an academic health system. J Am Med Inform Assoc 2020;27 (06):853-859 